\title{
The Knowledge of Nursing Internship Program Students about Early Detection of Sepsis
}

\author{
Stefani Stefani ${ }^{1} \mathbb{D}$, Yanny Trisyani $^{2} \mathbb{D}$, Anita Setyawati $^{2 *} \mathbb{D}$ \\ ${ }^{1}$ Bachelor Study Program, Faculty of Nursing, Universitas Padjadjaran, Bandung, Indonesia; ${ }^{2}$ Department of Critical Care and \\ Emergency Nursing, Faculty of Nursing, Universitas Padjadjaran, Bandung, Indonesia
}

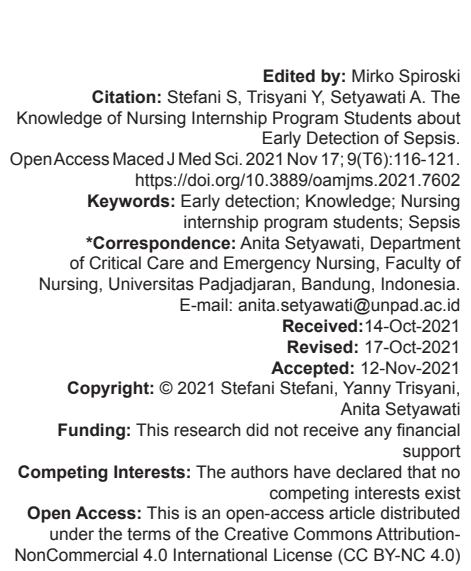

\section{Introduction}

Sepsis accounts for the highest mortality rate in hospitalized patients. One in three patients who die in the hospital experience sepsis (CDC, 2020). The World Health Organization (WHO) estimates that sepsis affects 30 million people worldwide each year with the potential for 6 million deaths (WHO, 2018). Observations conducted in the Intensive Care Unit (ICU) of Cipto Mangunkusumo Hospital Jakarta in 2012 showed that severe sepsis and sepsis shock incidence was $27 \%$, with the mortality rate in care reaching $47.8 \%$ and the mortality rate in the early phase reach $34.7 \%$ [1]. A high diagnosis of sepsis was also found in the internal medicine ward, which reached $10.3 \%$.

Sepsisisalife-threatening organ dysfunction due to failure to regulate the body's response to infection [2] The incidence of severe infections associated with organ damage is life-threatening because of the impaired body's response to infection [3], [4]. Decreased tissue perfusion and damage to several organs can occur due to impaired body response to infection and cause high patient mortality due to sepsis.
Sepsis has no single symptom and rapid diagnostic tests to help make decisions quickly. Sepsis is an emergency that requires prompt recognition, diagnosis, and appropriate treatment [5]. Early detection of septic patients and earlier treatment significantly reduce mortality [6], [7]. In addition, it is an essential step for sepsis management [8]. Early recognition will provide early management of sepsis that will minimize the deterioration of the patient's condition [4], [9].

The Third International Consensus Definitions for Sepsis and Septic Shock (Sepsis-3) recommended clinical criteria for sepsis in non-intensive care settings using a quick Sequential (sepsis-related) Organ Failure Assessment (qSOFA) [2]. qSOFA is a simple form of SOFA which only consists of three variables and does not require laboratory tests. Patients with a qSOFA score of two should be considered for the possibility of sepsis [10].

Sepsis guidelines adherence has been shown to reduce mortality in sepsis and septic shock [11]. In addition to reducing mortality, the application of sepsis guidelines reduces the time of antibiotic administration, treatment in the ICU, and increases the comparison of serum lactate measurements [12]. However, it is 
not straightforward for health workers to comply with existing guidelines. As a result, there are still obstacles that can reduce the quality of sepsis care.

Some factors have been shown to influence sepsis care. Knowledge is one of those factors [13], [14], [15]. Nurses need the knowledge to support identifying symptoms of sepsis and its worsening conditions in providing care for patients with severe illnesses in the ICU [16].

Knowledge is the basis of acting and behaving. Therefore, the level of knowledge is directly proportional to the understanding of acting [17]. Inadequate knowledge about sepsis will have a negative impact on attitudes and behaviors [18]. Screening and functional management of sepsis are achieved by ensuring adequate education for nursing staff [19]. In addition, knowledge and awareness of health workers about sepsis play a major role in identifying and treating patients at risk for sepsis [20]. Therefore, nurses need to have adequate knowledge to increase awareness of the importance of early detection of sepsis.

Sepsis care requires interprofessional collaboration, starting from laboratory assistants, pharmacists, and nurses [21]. Although sepsis management requires interprofessional collaboration, nurses play a role in improving sepsis management [22].

Nurses have a strategic position in interacting with patients to integrate sepsis screening. The ability of nurses to assess the vital signs and physical condition of patients is the primary key in identifying sepsis [23]. In addition, nurses must have sufficient education to recognize and effectively treat septic patients [24].

Nursing services cannot be separated from the educational process. Nursing education is the first step for nurses to become academics and professionals. Hence, nursing internship program students need to have sufficient knowledge about the early detection of sepsis. This study aimed to identify the knowledge of nursing internship program students regarding the early detection of sepsis and the demographic factor that contributed to the knowledge.

\section{Methods}

\section{Study design}

This research was a quantitative study that explored nursing internship program students' knowledge about the early detection of sepsis.

\section{Sample and settings}

Research was conducted at the Faculty of Nursing, Universitas Padjadjaran, Indonesia.
The proportionate stratified non-random sampling technique was used to sample the population. One hundred forty-three nursing internship program students of Universitas Padjadjaran participated in this study.

\section{Instruments}

The questionnaire used to measure knowledge was compiled based on the Sepsis-3 guidelines. The questionnaire consisted of two parts: the respondent's characteristics and thirteen questions to measure knowledge about early detection of sepsis.

The content validity test is carried out through expert judgment. The expert assessed that the questionnaire followed the concept and purpose of the study. Meanwhile, the face validity, construct validity, and reliability tests were carried out on 30 nursing internship program students of Universitas Padjadjaran. Respondents who took part in the instrument test were not included in the data analysis process. The results of the face validity test show that all respondents understand all of the question items. The construct validity test was carried out using bivariate analysis of the Pearson Product-Moment Correlation test. The reliability test was carried out with the Cronbach's Alpha test. The reliability test results were 0.622 , which means the question items have high reliability based on the Guilford coefficient classification [25].

\section{Data collection}

The research was conducted online in JulyAugust 2021 on respondents in Indonesia through the Google Form platform.

\section{Data analysis}

Data analysis used descriptive analysis and inferential statistics using the Mann-Whitney test. The results of the Kolmogorov-Smirnov normality test showed a value of $p=0.00$, which indicated that the data were not normally distributed $(p<0.05)$. The skewness value of -0.76 suggests that the data is not extremely skewed so the mean used to be a central tendency. The mean estimates the best central tendency because of its stability and is the most stable central tendency among the other two measurements [26].

\section{Ethical consideration}

The research received the ethical exemption from the Health Research Ethics Commission of Universitas Padjadjaran with letter number 551/UN6. KEP/EC/2021. 


\section{Results}

A total of 143 participants filled out the questionnaire completely. Based on Table 1, it is known that most of the respondents (86\%) are female, almost all respondents $(98.6 \%)$ are in the late adolescent age group (age 17-25 years), and were in the XLI class (78.3\%).

Table 1: Demographic Characteristics of Participants $(n=143)$

\begin{tabular}{|c|c|c|}
\hline Characteristics & Frequency & Percentage \\
\hline \multicolumn{3}{|l|}{ Gender } \\
\hline Male & 20 & 14 \\
\hline Female & 123 & 86 \\
\hline \multicolumn{3}{|l|}{ Age } \\
\hline Late adolescent (17-25 years) & 141 & 98.6 \\
\hline Early adulthood ( $26-35$ years) & 2 & 1.4 \\
\hline \multicolumn{3}{|l|}{ Batch } \\
\hline $\mathrm{XL}$ & 31 & 21.7 \\
\hline $\mathrm{XLI}$ & 112 & 78.3 \\
\hline \multicolumn{3}{|l|}{ Training about sepsis } \\
\hline Yes & 8 & 5.6 \\
\hline No & 135 & 94.4 \\
\hline \multicolumn{3}{|c|}{ Information about early detection of sepsis } \\
\hline Yes & 87 & 60.8 \\
\hline No & 56 & 39.2 \\
\hline \multicolumn{3}{|c|}{ Information about early detection of sepsis } \\
\hline Poster and leaflet & 18 & 12.6 \\
\hline Article/Journal & 48 & 33.8 \\
\hline Seminar/Symposium & 8 & 5.6 \\
\hline Book & 36 & 25.4 \\
\hline Lecture, Tutorial, etc. & 112 & 78.9 \\
\hline $\begin{array}{l}\text { Others (Internet, Video, } \\
\text { discussion) }\end{array}$ & 3 & 2.1 \\
\hline Never & 8 & 5.6 \\
\hline
\end{tabular}

Only a small proportion of respondents (5.6\%) have attended specific training on sepsis. However, more than half of the respondents $(60.8 \%)$ have received information about early detection of sepsis, with the majority of the information sources coming from the lecture process (lectures, tutorials, etc.) $(78.9 \%)$, articles/journals (33.8\%), and books (25.4\%).

Overall, the knowledge of nursing internship program students has an average score of 70.4 with a standard deviation $(S D)=11.9$ (Table 2). The knowledge score is divided into two categories based on the mean score: a knowledge score above the average and below the average. Although there was a slight difference between the two groups, more than half got a knowledge score below the average (56.6\%).

Table 2: Distribution of knowledge score of nursing internship program students sepsis about early detection of sepsis $(n=$ 143)

\begin{tabular}{|c|c|c|c|c|c|c|}
\hline \multirow[t]{2}{*}{ Variable } & \multirow[t]{2}{*}{ Mean } & \multirow[t]{2}{*}{ SD } & \multicolumn{2}{|c|}{ Score>Mean } & \multicolumn{2}{|c|}{ Score $<$ Mean } \\
\hline & & & $\mathrm{n}$ & $\%$ & $n$ & $\%$ \\
\hline $\begin{array}{l}\text { Knowledge about early detection } \\
\text { of sepsis }\end{array}$ & 70.4 & 11.9 & 62 & $43.4 \%$ & 81 & $56.6 \%$ \\
\hline $\begin{array}{l}\text { Knowledge of nursing internship } \\
\text { program student batch XL }\end{array}$ & 70.7 & 10.6 & 11 & $35.5 \%$ & 20 & $64.5 \%$ \\
\hline $\begin{array}{l}\text { Knowledge of nursing internship } \\
\text { program student batch } \mathrm{XLI}\end{array}$ & 70.3 & 12.3 & 51 & $45.5 \%$ & 61 & $54.5 \%$ \\
\hline
\end{tabular}

Table 3 shows that there are several gaps in respondents' correct answers per item question when viewed based on their batch. All students from group $\mathrm{XL}$ $(100 \%)$ were able to answer two question items correctly, the question "getting a surgical procedure or invasive procedure" on the risk factors of sepsis and "systolic blood pressure $100 \mathrm{mmHg}$ " on the qSOFA criteria. Meanwhile, group XLI students answered the question items correctly were "have impaired immunity" on risk factors for sepsis. However, the two groups mostly answered incorrectly on the question "the patient's body temperature shows more than $38^{\circ} \mathrm{C}$ " in determining the qSOFA criteria.

Table 3: Distribution of correct answers to early detection of sepsis of different groups $(n=143)$

\begin{tabular}{|c|c|c|c|c|}
\hline \multirow[t]{2}{*}{ Questions } & \multicolumn{2}{|c|}{ Batch XL } & \multicolumn{2}{|c|}{ Batch XLI } \\
\hline & $\mathrm{n}$ & $\%$ & $\mathrm{n}$ & $\%$ \\
\hline \multicolumn{5}{|l|}{ Definition of sepsis } \\
\hline $\begin{array}{l}\text { Which of the following is the current definition of } \\
\text { sepsis? }\end{array}$ & 10 & $32 \%$ & 25 & $22 \%$ \\
\hline \multicolumn{5}{|l|}{ Risk factors of sepsis } \\
\hline Very old or very young people & 20 & $65 \%$ & 87 & $78 \%$ \\
\hline Have impaired immunity & 28 & $90 \%$ & 105 & $93 \%$ \\
\hline Getting a surgical procedure or invasive procedure & 31 & $100 \%$ & 102 & $91 \%$ \\
\hline Experiencing damage to skin integrity & 29 & $94 \%$ & 102 & $91 \%$ \\
\hline Mean & & $87 \%$ & & $88 \%$ \\
\hline \multicolumn{5}{|l|}{ Clinical criteria of sepsis based on qSOFA } \\
\hline The patient's body temperature is more than $38^{\circ} \mathrm{C}$ & 4 & $13 \%$ & 13 & $12 \%$ \\
\hline The patient's heart rate is less than 90 beats/min & 14 & $45 \%$ & 54 & $48 \%$ \\
\hline $\begin{array}{l}\text { The patient's respiratory rate is } 22 \text { breaths/min or } \\
\text { more }\end{array}$ & 26 & $84 \%$ & 99 & $88 \%$ \\
\hline GCS $<15$ & 26 & $84 \%$ & 100 & $89 \%$ \\
\hline Systolic blood pressure $\leq 100 \mathrm{mmHg}$ & 31 & $100 \%$ & 91 & $81 \%$ \\
\hline Mean & & $65 \%$ & & $64 \%$ \\
\hline \multicolumn{5}{|l|}{ Sepsis case scenario } \\
\hline Case 1 & 30 & $97 \%$ & 103 & $92 \%$ \\
\hline Case 2 & 24 & $77 \%$ & 88 & $79 \%$ \\
\hline Case 3 & 12 & $39 \%$ & 54 & $48 \%$ \\
\hline Mean & & $71 \%$ & & $73 \%$ \\
\hline
\end{tabular}

There was a significant positive correlation found in this study between information and knowledge about early detection of sepsis with the $p=0.002$ (Table 4). The findings indicate that information of early detection of sepsis increases the nursing internship program students' knowledge.

\section{Discussion}

Based on the research results, the average knowledge score about early detection of sepsis of nursing internship program students of Universitas Padjadjaran is $70.4(\mathrm{SD}=11.9)$. However, there are several gaps found. More than half of the respondents scored below the average. In addition, almost all respondents did not know the current definition of sepsis and incorrectly identified a patient's body temperature $>38^{\circ} \mathrm{C}$ as clinical criteria for sepsis based on the qSOFA score. Meanwhile,

Table 4: Difference between participant's personal characteristics and knowledge scores on early detection of sepsis $(n=143)$

\begin{tabular}{llll}
\hline Characteristics & Mean & SD & p-value \\
\hline Gender & & & 0.06 \\
$\quad$ Male & 65.4 & 13.6 & \\
$\quad$ Female & 71.2 & 11.5 & 0.298 \\
Age & 70.3 & 11.9 & \\
$\quad$ Late & & & \\
$\quad$ adolescent (17-25 years) & 76.9 & 0.0 & \\
$\quad$ Early & & & 0.604 \\
$\quad$ adulthood (26-35 years) & & 10.6 & \\
Batch & 70.7 & 12.3 & 0.243 \\
$\quad$ XL & 70.3 & & \\
$\quad$ XLI & & 17.3 & 0.002 \\
$\quad \begin{array}{l}\text { Training about sepsis } \\
\quad \text { Yes }\end{array}$ & 63.5 & 11.5 & \\
$\quad$ No \\
Information about early detection of sepsis \\
$\quad 70.7$ & & \\
$\quad$ Yes & 72.7 & 11.4 & \\
$\quad$ No & 66.8 & 11.9 & \\
\hline
\end{tabular}


based on its characteristics, the information is a factor that significantly affects the knowledge score $(p<0.05)$.

The definition of sepsis has evolved and changed since it was first published in 1991. Currently, sepsis is defined as a life-threatening organ dysfunction caused by dysregulation of the body's response to infection [27]. However, most of the respondents do not know the current definition of sepsis. It is in contrast with the research conducted by Tilton (2019) that most nursing students $(60 \%)$ answered questions about the definition of sepsis according to the Sepsis-3 guidelines [28]. Nursing internship program students need to know the current definition of sepsis because the definition of Systemic Inflammatory Response Syndrome (SIRS) as sepsis is considered less specific in identifying sepsis.

The definition of Sepsis-2 that uses the SIRS as clinical criteria for sepsis leads to an overdiagnosis of patients with infections identified as sepsis and results in low specificity in detecting sepsis [27], [29]. SIRS criteria are considered too sensitive and non-specific, causing overdiagnosis and inappropriate antibiotic administration [30]. Patients presenting to the ED may exhibit SIRS criteria in various situations, including metabolic and endocrine disease, cancer, respiratory syndrome, infection, trauma, and ischemia [31].

Patients at high risk for sepsis usually have several comorbidities. Therefore, various populations at high risk of sepsis need more intensive assessment and monitoring of worsening conditions [32]. By knowing the risk factors for sepsis, it is hoped that nursing internship program students can increase their vigilance to carry out further assessment and monitoring to prevent septic shock due to a decrease in the condition of patients at risk of sepsis.

Knowledge of signs, symptoms, and appropriate care in septic patients is essential for successfully managing sepsis [33]. Based on the study results, more than half of the respondents (64\%) were able to correctly answer questions regarding clinical criteria for sepsis based on qSOFA. It is in contrast to a study conducted by Tilton (2019) which found that only a small proportion of nursing students (22\%) were able to identify sepsis screening measurements based on qSOFA. Thus, it proves that although respondents do not know the updated definition of sepsis based on the Sepsis-3 guidelines, respondents know the qSOFA indicators as clinical criteria for sepsis. Furthermore, López-Izquierdo et al. (2020) also stated in their research that the qSOFA score could be used as an initial assessment to detect patients at high risk of sepsis [34]. Thus, it is expected that knowing the clinical criteria for sepsis based on qSOFA respondents can have good behavior in the early detection of sepsis.

However, respondents still cannot distinguish the criteria for patient body temperature $>38^{\circ} \mathrm{C}$ as clinical criteria for sepsis based on qSOFA. Most respondents still use the definition of sepsis based on
Sepsis-2, which uses SIRS criteria. Body temperature is a poor indicator of sepsis because fever is not always present, especially in immunocompromised patients [3]. In addition, hypothermic sepsis patients are associated with higher mortality rates [35]. Therefore, whether the patient's body temperature is high or low, both need to be given appropriate treatment.

Information obtained through both formal and informal education can lead to changes in increasing knowledge [36]. In line with this statement, the study results indicate that information has a significant effect on knowledge scores. Furthermore, most students get information about the early detection of sepsis from the lecture process. Therefore, students need to increase their knowledge through the various information they receive.

A person's perception and mindset are influenced by age. Therefore, increasing age will facilitate the development of capture power and perspective so that the knowledge gained will be better [36]. Respondents in this study were classified as homogeneous based on their age. Based on statistical tests, age is considered not to have a significant effect on knowledge scores.

According to other demographic status, students in the XLI class and students who had never attended special training on sepsis got a knowledge score below the average. These results are in line with research conducted by Harley et al., (2021), which identified a significant difference between students who had received formal education about sepsis and the total knowledge score [37]. The importance of this role of formal education on the level of knowledge has also been identified [38], [39]. It is also important to ensure that training is delivered in a frequency and range not too far apart. Research by Nucera et al. (2018) shows that special training significantly affects knowledge scores about sepsis, but this increase can last for a certain period, which is about 6 months [40]. Therefore, to be able to maintain good knowledge, continuous and comprehensive training is needed.

Effective educational interventions are needed to assess sepsis patients accurately and quickly [41]. Nursing professional students need to understand current sepsis guidelines and use sepsis screening tools to perform early detection appropriately and initiate appropriate treatment. Nursing faculties need to implement teaching strategies that facilitate students to acquire knowledge, skills, and attitudes that will improve patient outcomes and reduce preventable medical errors [42].

A study conducted by Davis et al., (2016) stated that preparing a teaching package on sepsis is an opportunity to support the knowledge needed to understand sepsis and how it affects patients. The teaching package offered is a PowerPoint presentation to introduce case studies and the physiological process of sepsis. In addition, using various technologies produces 
a modern look and facilitates interactive learning. Thus, it is intended to increase learning effectiveness [44].

In addition, a unique learning method was introduced by Evans et al. (2015) by utilizing an online game using a free, accessible, and easy-to-use platform, namely Septris [45]. Septris provides an interactive, casebased learning environment. This game provides real-time feedback to support experiential learning. This learning method has been tested on students, which showed a significant increase in knowledge $(p<0.001)$ after students played the game in $20 \mathrm{~min}$. This method is considered an easy and inexpensive way that students can do.

There is limited literature that discusses nursing students' knowledge about the early detection of sepsis. Most research on sepsis was conducted on nurses, doctors, and other health workers, not on nursing students. Therefore, it is difficult for researchers to compare the results of this study with other studies that have been conducted. Further research can considerably investigate this topic considering that there are still limited studies examining the knowledge of nursing profession students about sepsis.

\section{Conclusion}

The results showed that nursing internship program students of Universitas Padjadjaran had a fairly good average score of knowledge about early detection of sepsis. However, more than half of the students scored below the group average. Furthermore, the information is a factor that significantly influences the knowledge score.

Based on the research, nursing institutions are expected to provide case-based education methods through the lecture process by implementing an interactive strategy to introduce Sepsis-3 guidelines, clinical criteria for sepsis based on qSOFA, and distinguish SIRS from sepsis. In addition, online games can also be applied as experiential learning for nursing professional program students to improve critical thinking processes in making decisions. Training, whether in workshops, seminars, or skills trainings, can be provided to students to increase and maintain knowledge about the early detection of sepsis. Further research can explore what factors can affect the knowledge of nursing profession program students so that later specific interventions can be carried out.

\section{References}

1. Republik Indonesia. Decree of the Minister of Health of the Republic of Indonesia Number HK.01.07/MENKES/342/2017 About National Guidelines for Medical Services for the
Management of Sepsis. Jakarta: Kementerian Kesehatan; 2017.

2. Rhodes A, Evans LE, Alhazzani W, Levy MM, Antonelli M, Ferrer $\mathrm{R}$, et al. Surviving sepsis Campaign: International guidelines for management of sepsis and septic shock : 2016. Crit Care Med. 2017;45(3):486-552. https://doi.org/10.1097/ ccm. 0000000000000192

PMid:28101605

3. Hunt A. Sepsis : An overview of the signs, symptoms, diagnosis, treatment and pathophysiology. Emerg Nurse. 2019;27(5):32-41. https://doi.org/10.7748/en.2019.e1926

PMid:31475503

4. Cohen J, Vincent JL, Adhikari NK, Machado FR, Angus DC, Calandra T, et al. Sepsis : A roadmap for future research. Lancet Infect Dis. 2015;15(5):581-614.

PMid:25932591

5. Proffitt RD, Hooper G. Evaluation of the (qSOFA) tool in the emergency department setting: Nurse perception and the impact on patient care. Adv Emerg Nurs J. 2020;42(1):54-62. https://doi.org/10.1097/tme.0000000000000281

PMid:32000191

6. Christ M. How to manage sepsis in the emergency department leading to a decreased mortality in ICU-the critical care cascade. Acute Care Test. 2011. Available from: https://acutecaretesting. org/en/articles/how-to-manage-sepsis-in-the-emergencydepartment-leading-to-a-decreased-mortality-in-icu.

7. Heather A, Bruce R, Maiden J, Fedullo PF, Kim SC. Impact of nurse-initiated sepsis protocol on compliance with sepsis bundles, time ti initial antibiotic, administration, and in-hospital mortality. J Emerg Nurs. 2015;41(2):130-7. https://doi. org/10.1016/j.jen.2014.12.007

PMid:25612516

8. Schorr C. Surviving sepsis campaign: Hour-1 bundle. Am Nurse Today. 2018;13(9):16-9.

9. Harley A, Johnston AN, Denny KJ, Keijzers G, Crilly J, Massey D. Emergency nurses' knowledge and understanding of their role in recognising and responding to patients with sepsis : A qualitative study. Int Emerg Nurs. 2019;43:106-12. https://doi. org/10.1016/j.ienj.2019.01.005

PMid:30733005

10. Kim HI, Park S. Sepsis: Early recognition and optimized treatment. Tuberc Respir Dis (Seoul). 2019;82(1):6-14. https:// doi.org/10.4046/trd.2018.0041 PMid:30302954

11. Ahn S, Song J, Moon S, Cho H, Kim JY, Park J. Association between compliance with Surviving Sepsis Campaign guidelines and outcomes among sepsis and septic shock patient in accordance with Sepsis-3 definitions. J Korean Soc Emerg Med.2020;31(1):45-51. https://doi.org/10.3390/jcm8111800

12. Sungkar $\mathrm{Y}$, Considine J, Hutchinson A. Implementation of guidelines for sepsis management in emergency departments: A systematic review. Australas Emerg Care. 2018;21(4):111-20. https://doi.org/10.1016/j.auec.2018.10.003 PMid:30998886

13. Cowan SL, Holland JA, Frost I, Kane AD. Recognition and management of sepsis by junior doctors. Futur Hosp J. 2016;3(2):99-102. https://doi.org/10.7861/futurehosp.3-2-99 PMid:31098196

14. Breen SJ, Rees S. Barriers to implementing the sepsis six guidelines in an acute hospital setting. $\mathrm{Br} J$ Nurs. 2018;27(9):473-8. https://doi.org/10.12968/bjon.2018.27.9.473 PMid:29749778

15. Burney M, Underwood J, McEvoy S, Nelson G, Dzierba A, Kauari $\mathrm{V}$, et al. Early detection and treatment of severe sepsis in the emergency department: Identifying barriers to implementation of a protocol-based approach. J Emerg Nurs. 
2012;38(6):512-7. https://doi.org/10.1016/j.jen.2011.08.011 PMid:22079648

16. Melquiades J, Campos DA, de Araújo Marques LB, de Oliveira Couras Ramalho CR, da Nóbrega MM. Conception of nurses who work in a general intensive care unit regarding sepsis. Cogitare Enferm. 2015;20(4):706-11.

17. Nofiyanto $M$, Munif $M$, Darussalam M. Pengetahuan dan sikap perawat tentang mobilisasi dini pasien di ICU rsud panembahan senopati bantul Yogyakarta. Media IImu Kesehat. 2019;6(1):9-17. https://doi.org/10.30989/mik.v6i1.173

18. Park J, Hwang SY, Shin TG, Jo IJ, Yoon H, Lee TR, et al. Emergency medical service personnel need to improve knowledge and attitude regarding prehospital sepsis care. Clin Exp Emerg Med. 2017;4(1):48-55. https://doi.org/10.15441/ ceem.16.159

PMid:28435902

19. Kleinpell R. Promoting early identification of sepsis in hospitalized patients with nurse-led protocols. Crit Care. 2017;21(1):10-2. https://doi.org/10.1186/s13054-016-1590-0

PMid:28073375

20. Seymour CW, Carlbom D, Engelberg RA, Larsen J, Bulger EM, Copass MK, et al. Understanding of sepsis among emergency medical services: A survey study. J Emerg Med. 2012;42(6):666-77

21. Kliger J, Singer SJ, Hoffman FH. Using the integrated nurse leadership program to reduce sepsis mortality. Joint Comm J Qual Patient Saf. 2015;41(6):264-72. https://doi.org/10.1016/ s1553-7250(15)41036-0 PMid:25990892

22. Mcveigh SE. Sepsis menegement in the emergency department. Nurs Clin North Am. 2019;55(1):71-9.

PMid:32005367

23. Drahnak DM, Hravnak M, Ren D, Haines AJ, Tuite P. Scripting nurse communication to improve sepsis care. Medsurg Nurs. 2015;25:233-9.

24. McCaffery M, Onikoyi O, Rodrigopulle D, Syed A, Jones S, Mansfield L, et al. Sepsis-review of screening for sepsis by nursing, nurse driven sepsis protocols and development of sepsis hospital policy/protocols. Nurs Palliat Care. 2016;1:33-7. https://doi.org/10.15761/npc.1000109

25. Putri HE, Wahyudy MA, Yuliyanto A, Nuraeni F. Development of instruments to measure mathematical anxiety of elementary school students. Int J Learn Teach Educ Res. 2020;19(6):282302. https://doi.org/10.26803/ijlter.19.6.17

26. Polit DF, Beck VT. Nursing Research: Generating and Assessing Evidence for Nursing Practice. China: Wolters Kluwer; 2017.

27. Singer M, Deutschman CS, Seymour CW, Shankar-Hari M, Annane $\mathrm{D}$, Bauer $\mathrm{M}$, et al. The third international consensus definitions for sepsis and septic shock (sepsis-3). JAMA. 2016;315(8):801-10. PMid:26903338

28. Tilton KE. Sepsis Knowledge in Undergraduate Nursing Students, Undergrad Theses. China: Honor; 2019.

29. Schmedding M, Adegbite BR, Gould S, Beyeme JO, AdegnikaAA, Grobusch MP, et al. A prospective comparison of quick sequential organ failure assessment, systemic inflammatory response syndrome criteria, universal vital assessment, and modified early warning score to predict mortality in patients with suspected infection in Gabon. Am Soc Trop Med Hyg. 2019;100(1):202-8. https://doi.org/10.4269/ajtmh.18-0577 PMid:30479248

30. Spoto $S$, Nobile $E$, Carnà EP, Fogolari M, Caputo D, De Florio L, et al. Best diagnostic accuracy of sepsis combining SIRS criteria or qSOFA score with procalcitonin and mid-regional proadrenomedullin outside ICU. Sci Rep. 2020;10(1):1-11. https:// doi.org/10.1038/s41598-020-73676-y
31. Horeczko T, Green JP, Panacek EA. Epidemiology of the systemic inflammatory response syndrome (SIRS) in the emergency department. West J Emerg Med. 2014;15(3):329-36. https://doi.org/10.5811/westjem.2013.9.18064 PMid:24868313

32. Rowe A, McClelland A, Billingham K. Community Health Needs Assessment: An Introductory Guide for the Family Health Nurse in Europe. Geneva: World Health Organization; 2001.

33. Adegbite BR, Edoa JR, Rylance J, Jacob ST, Kawal P, Adegnika $A A$, et al. Knowledge of health workers relating to sepsis awareness and management in Lambaréné, Gabon. Acta Trop. 2021;219:1-7.

34. López-Izquierdo R, Del Brio-lbañez P, Martín-Rodríguez $F$, Mohedano-Moriano A, Polonio-López B, Maestre-Miquel C, et al. Role of qSOFA and SOFA scoring systems for predicting in-hospital risk of deterioration in the emergency department. Int J Environ Res Public Health. 2020;17(22):8367. https://doi. org/10.3390/ijerph17228367

PMid:33198151

35. Wiewel MA, Harmon MB, van Vught LA, Scicluna BP, Hoogendijk AJ, Horn J, et al. Risk factors, host response and outcome of hypothermic sepsis. Crit Care. 2016;20(1):1-9. PMid:27737683

36. Budiman B, Riyanto A. Capita Selecta Knowledge and Attitude Questionnaire in Health Research. Jakarta: Salemba Medika; 2013.

37. Harley A, Massey D, Ullman AJ, Reid-Searl K, Schlapbach LJ, Takashima M, et al. Final year nursing student's exposure to education and knowledge about sepsis: A multi-university study. Nurse Educ Today. 2021;97:104703. https://doi.org/10.1016/j. nedt.2020.104703

38. Delaney MM, Friedman MI, Dolansky MA, Fitzpatrick JJ. Impact of a sepsis educational program on nurse competence. J Contin Educ Nurs. 2015;46(4):179-86. https://doi. org/10.3928/00220124-20150320-03

39. Storozuk SA, Macleod ML, Freeman S, Banner D. Australasian emergency care a survey of sepsis knowledge among Canadian emergency department registered nurses. Australas Emerg Care. 2019;22(2):119-25. https://doi.org/10.1016/j. auec.2019.01.007

PMid:31042531

40. Nucera G, Esposito A, Tagliani N, Jane Baticos C, Marino P. Physicians' and nurses' knowledge and attitudes in management of sepsis: An Italian study. J Health Soc Sci. 2018;3(1):13-26.

41. Kim B, Jeong Y. Effects of a case-based sepsis education program for general ward nurses on knowledge, accuracy of sepsis assessment, and self-efficacy. J Korean Biol Nurs Sci. 2017;22(4):260-70. https://doi.org/10.7586/jkbns.2020.22.4.260

42. Jones $A D$. The impact of integrating quality and safety education for nurses' safety competency in first-year associate degree nursing students. Teach Learn Nurs. 2013;8(4):140-6. https:// doi.org/10.1016/j.teln.2013.06.001

43. Davis A, Henderson J, Langmack G. Development of an e-learning package for sepsis care. Br J Nurs. 2016;25(6):292-6. PMid:27019164

44. Windle RJ, McCormick D, Dandrea J, Wharrad H. The characteristics of reusable learning objects that enhance learning: A case-study in health-science education. $\mathrm{Br} J$ Educ Technol. 2011;42(5):811-23. https://doi. org/10.1111/j.1467-8535.2010.01108.x

45. Evans KH, DainesW, Tsui J, Strehlow M, MaggioP, ShiehL. Septris: A novel, mobile, online, simulation game that improves sepsis recognition and management. Acad Med. 2015;90(2):180-4. https://doi.org/10.1097/acm.0000000000000611 PMid:25517703 